\title{
Effects of Different Pre-processing Methods on Dry Anaerobic Fermentation of Sugarcane Leaves and Pig Manure
}

\author{
Xiaohong Huang, Jing Jiao*, Jihua Du, Zunxiang Li \\ Institute of Agricultural Machinery, Chinese Academy of Tropical Agricultural Sciences (CATAS), Zhanjiang 524091, China
}

\begin{abstract}
Using agricultural wastes for anaerobic fermentation to produce biogas can not only realize the resource utilization of the wastes, but also prevent the environmental issues caused by straw burning. Sugarcane leaves contain waxy layer, which will cause problems such as difficulty in degradation, long-time fermentation and low biogas production. This paper studies the effects on three pre-processing methods of adding rush rot agent, natural retting for 7 days and water moisture for 24 hours of dry anaerobic fermentation of sugarcane leaves and pig manure. The results show that natural retting for 7 days has the advantage of daily biogas production when the fermentation period is less than 20 days, but this method is not obviously different from that of water moisture for 24 hours. When taking total biogas production volume and volume loading rate as the indicators, water moisture for 24 hours is the best pre-processing method for dry anaerobic fermentation of sugarcane leaves and pig manure when the fermentation period is more than 20 days.
\end{abstract}

\section{Introduction}

Anaerobic digestion technology is an effective way for resource utilization and energy utilization of agricultural and breeding wastes.Sugarcane leaves are the main wastes in the harvesting process. It is estimated that for every 1 ton sucrose produced, 1 2 tons sugarcane leaves will be wasted [1-2]. Cellulose content in the sugarcane leaves is about $50 \%$ and it's the excellent raw material for producing biogas[3]. When having anaerobic digestion, it may cause low degradation, long-time fermentation and other problems as the leaves contain large amount of lignin. [4-5] Therefore, the straw needed to be pre-processed for destroying the structure of lignocellulose to increase its biodegrability. The common pre-processing includes heat treatment [6], chemical treatment [4], biological treatment[5], physical treatment[7] and combination of various pre-processing methods[8]. Among these, biological treatment has moderate conditions, good effects, low energy consumption and no pollution, which becomes a research focus[9]. However, the culture of bacteria (white rot fungi, complex bacteria) is complicated, and the pre-processing time is long, which makes it difficult to use in engineering production. Jing Jiao et al. [10] carried out the orthogonal experiment on sugarcane leaves dry anaerobic fermentation. The maximum biogas production volume was $655.30 \mathrm{~L}$ under the condition of 1:1 mass ratio of grass and manure and $38{ }^{\circ} \mathrm{C}$ fermentation temperature in natural retting. And they thought that adding Lv Jie Ling and rush rot agent had no effect on sugarcane leaves fermentation when retting. This experiment aims to explore the effects of three different pre-processing (adding Rylatt rush rot agent, natural retting for 7 days and water moisture for 24 hours) methods on sugarcane leaves dry anaerobic fermentation, study the feasibility of straw pre-processing with microorganism from raw materials and provide theoretical reference and scientific support for improving the anaerobic digestion performance and biogas production efficiency of mixed materials.

\section{Materials and Methods}

\subsection{Materials}

Sugarcane leaves: Dried yellow leaves of sugarcane harvested from Experimental Base of South Subtropical Crops Research Institute, Chinese Academy Of Tropical Agricultural Sciences, Mazhang District, Zhanjiang, baled storage (moisture content: 13.00\%, C\%: 67.85\%, N\%: $0.46 \%$ ), crushed to less than $5 \mathrm{~cm}$ before using.

Pig manure: From Gaoyang Individual Pig Farm in Zhanjiang (moisture content: $75.00 \%, \mathrm{C} \%: 13.28 \%$, N\%: $0.87 \%$ )

Inoculum: Substrate for normal fermentation of Biogas Base of Agricultural Machinery Institute, Chinese Academy of Tropical Agricultural Sciences (Fermentation substrate from pig manure, domestic sewage sludge and sugarcane leaves)

\subsection{Experimental Device}

The experimental device is a controllable water bath

"Corresponding author's e-mail: eddweiss@163.com 
constant temperature anaerobic fermentation device made by Agricultural Machinery Institute, Chinese Academy of Tropical Agricultural Sciences, with a tank volume of $40 \mathrm{~L}$. It consists of the tank, heating insulation system and biogas metering system. As is shown in Figure 1.

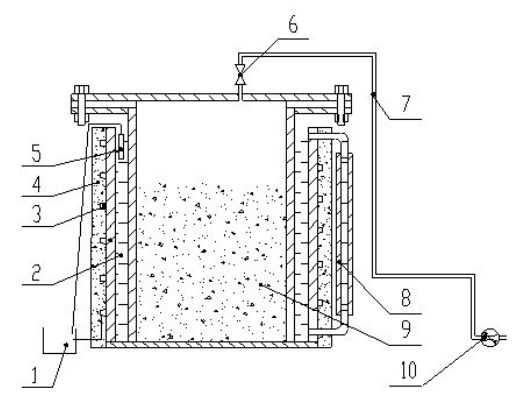

Figure 1. 1.Temperature controller 2. water 3.Heater 4. Insulation materials 5. Temperature sensor 6. Exhaust valve 7 . Rubber hose 8. Transparent rubber hose 9. Fermentation raw materials 10. Flow-meter

\subsection{Experimental Method}

\subsubsection{Raw Materials Pre-processing}

- Natural retting for 7 days pre-processing: Add pig manure with dry matter ratio of $1: 1$ to the crushed sugarcane leaves, adjust the $\mathrm{C} / \mathrm{N}$ value to 25 : 1 with urea, adjust the moisture to $80 \%$ with water, and cover with a plastic film, and complete natural retting for 7 days pre-processing.

- Rylatt rush rot agent pre-processing: Soak Rylatt rush rot agent with clear water for 24 hours, pour it into the mixture of sugarcane leaves and pig manure with dry matter ratio of 1 : 1 , adjust the $\mathrm{C} / \mathrm{N}$ value to $25: 1$ with urea, adjust the moisture to $80 \%$ with water, and complete Rylatt rush rot agent pre-processing.

- Water moisture for 24 hours pre-processing: Add water to crushed sugarcane leaves to adjust the moisture to $80 \%$, after mixing well, moist for 24 hours, add pig manure with dry matter ratio of 1: 1 to the wet sugarcane leaves, adjust the $\mathrm{C} / \mathrm{N}$ value to $25: 1$ with urea, adjust the moisture of mixture to $80 \%$ again, stir well, and complete the pre-processing.

2.3.2Anaerobic fermentation Add 30\% anaerobic fermentation inoculum to each pre-processing group and stir well. The solid content in the fermentation, $\mathrm{PH}$ value is about 7 8, coefficient of charging is 70\%. All groups have fermentation at $38{ }^{\circ} \mathrm{C}$ and the biogas production is measured regularly every day. After the biogas production is stable, Methane content and $\mathrm{H} 2 \mathrm{~S}$ content are measured in each processing gas.

\section{Results and Analysis}

\subsection{Effects of different pre-processing methods on the daily biogas production of sugarcane leaves and pig manure}

As is shown in the Figure 2, each group can produce biogas in a short time and have low biogas production in the first 6 days. Then they reach the peak of biogas production in the $6^{\text {th }} \sim 7^{\text {th }}$ day and there is a decrease. But the daily biogas production in all groups in 6 30 days is lager than that in the first 6 days. This indicated that with the fermentation, the waxy layer of sugarcane leaves is destroyed by microorganisms and enzymes and exposes the cellulose and hemicellulose with pig manure to increase biogas production. Adding biogas rush rot agent helps to start anaerobic fermentation faster with the maximum production in 24 hours. After reaching the peak of biogas production in the $7^{\text {th }}$ day, the production drops sharply. It gradually decreases with the prolongation of fermentation time, and there is only one peak of biogas production during fermentation. The daily biogas production of natural retting for 7 days ranks the first in the first 20 days of fermentation and the production drops slowly after reaching the peak of biogas production in the $7^{\text {th }}$ day. The daily biogas production in the fermentation in the first 20 days of water moisture for 24 hours group is not significantly different from that of natural retting for 7 days group. The two groups have almost the same biogas production in the $20^{\text {th }}$ day during the fermentation. After 20 days' fermentation, the daily biogas production of water moisture for 24 hours group is higher than that of natural retting for 7 days group. It appears the second peak of biogas production in the $26^{\text {th }}$ $\sim 32^{\text {nd }}$ day, which is the only pre-processing method that has two peaks among the three methods. Therefore, from the perspective of improving equipment utilization and shortening fermentation time, natural retting for 7 days is relatively suitable, and water moisture for 24 hours has the advantages of light process simplification and small site investment. When the fermentation cycle is less than 20 days, the biogas production is close to that of natural retting for 7 days group, and when the fermentation cycle is longer than 20 days, the biogas production of this method is the largest. 


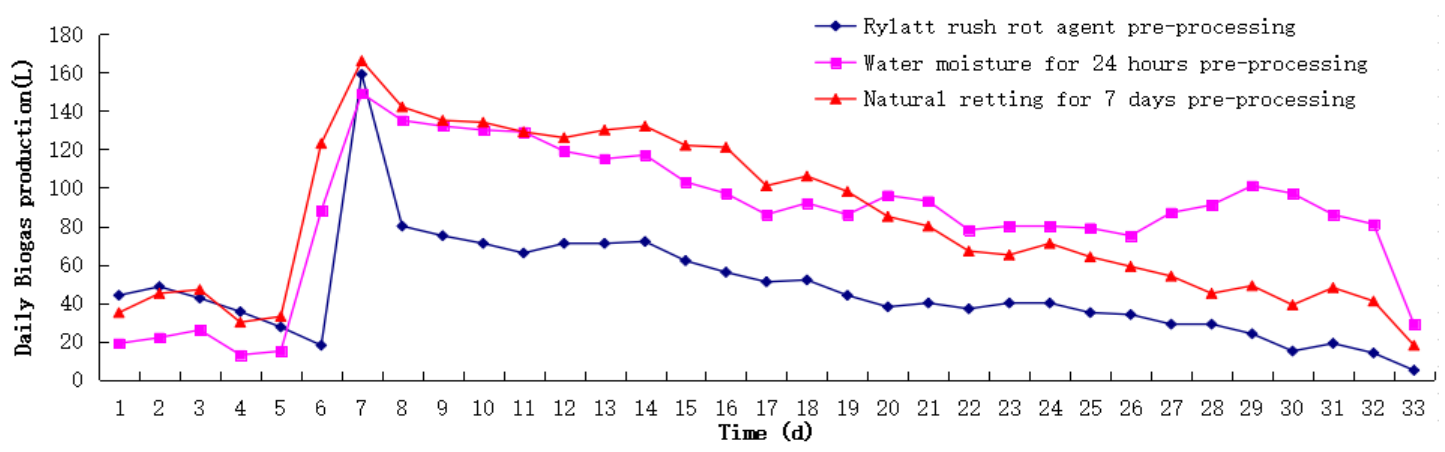

Figure 2. The daily biogas production of different pre-processing methods varies with fermentation time

\subsection{Effects of different pre-processing methods on the cumulative biogas production of sugarcane leaves and pig manure}

As can be seen in the Figure 3, the cumulative biogas production of water moisture for 24 hours straight up in the $33^{\text {th }}$ day of fermentation, the cumulative biogas production of other two methods gradually become parallel as the fermentation time increases.

In the first 20 days of fermentation, the cumulative biogas production of water moisture for 24 hours is not different from that of natural retting for 7 days. After the $21^{\text {st }}$ day, it is rapidly higher than natural retting for 7 days group. When the fermentation cycle is 33 days, water moisture for 24 hours group has the highest total biogas production, $2359.7 \mathrm{~L}$, which is $261.87 \mathrm{~L}$ higher than natural retting for 7 days group. It is the total biogas production of natural retting for 7 days group in the first three days. The total biogas production of water moisture for 24 hours group is $1128.7 \mathrm{~L}$ higher than adding rush rot agent, which is the 2 times the total biogas production of this group. The volume loading rate of water moisture for 24 hours group is $1.79 \mathrm{~L} / \mathrm{L} \cdot \mathrm{d}^{-1}$, higher than $1.59 \mathrm{~L} / \mathrm{L}^{-1} \mathrm{~d}^{-1}$, that of natural retting for 7 days group. Adding rush rot agent has the lowest volume loading rate of $1.00 \mathrm{~L} / \mathrm{L}^{-1} \mathrm{~d}^{-1}$. Therefore, from the perspective of total biogas production and volume loading rate, it is considered that the water moisture for 24 hours is the best pre-processing method for dry anaerobic fermentation of sugarcane leaves.

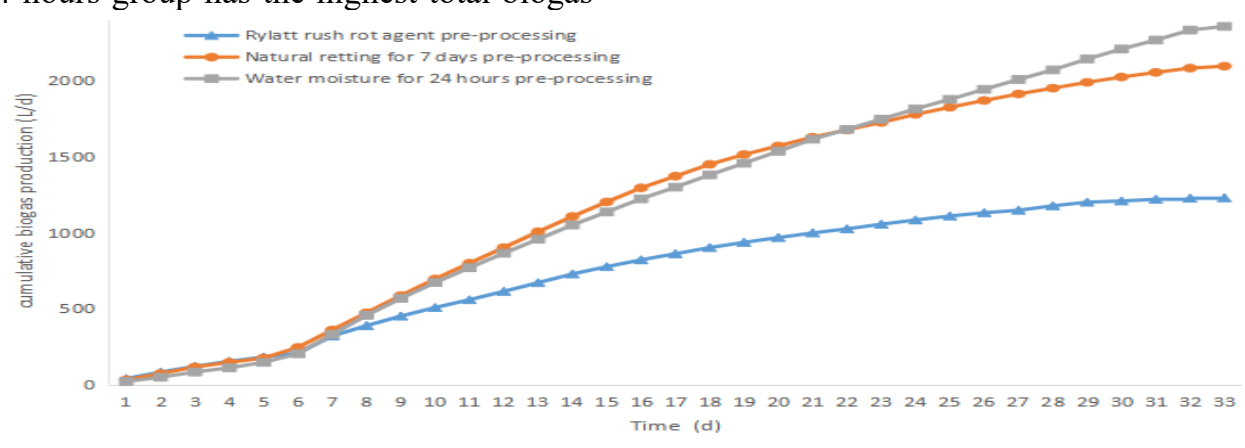

Figure 3. Changes in cumulative biogas production with different pre-pressing methods

\subsection{Effects of different pre-processing methods on methane production by anaerobic fermentation of sugarcane leaves and pig manure}

As we can see from the Figure 4, the methane content of adding rush rot agent group decreases with the prolongation of fermentation time. The highest methane content is $53.4 \%$, and the lowest methane content is $41 \%$, which indicates that the methanogens become weaker with the progress of fermentation. The methane content of natural retting for 7 days group increases and then decreases, the highest methane content at the 20 days of fermentation is $53.5 \%$, the lowest is $52.7 \%$, which is not obviously different. The methane content of water moisture for 24 hours group gradually increases with the prolonged fermentation time, the highest is $55.1 \%$. Therefore, it is believed that the different pre-processing methods have no significant effect on methane production in the early stage of anaerobic fermentation of sugarcane leaves and pig manure, but with the prolongation of fermentation time, water moisture for 24 hours is more conducive to promoting the conversion and utilization of substrates, which increases the methane production rate and improves the performance of anaerobic fermentation. 


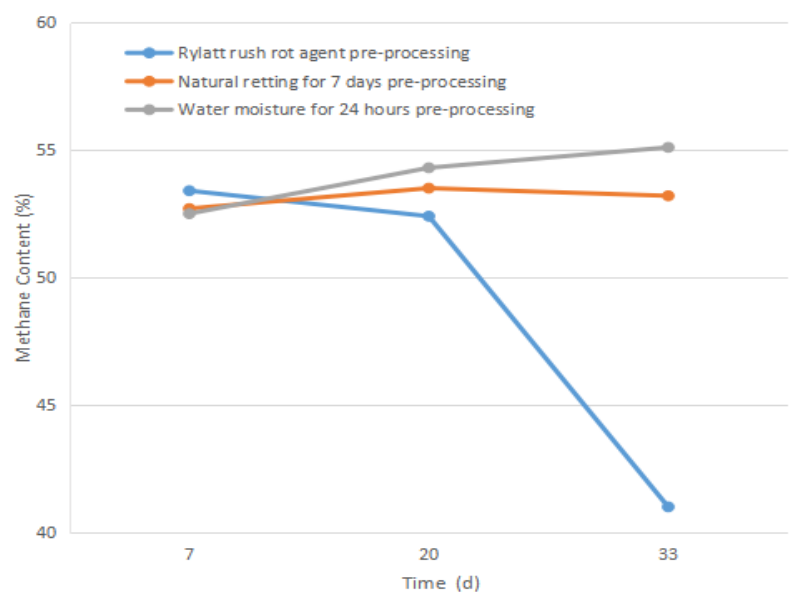

Figure 4. Changes of methane content during dry anaerobic fermentation of each method

\section{Conclusion}

This paper studies the effects of different pre-processing methods on the performance of dry anaerobic fermentation of sugarcane leaves and pig manure, and draws the following conclusions:

- Adding rush rot agent can accelerate the start time of fermentation, but it does not improve the ability of sugarcane leaves and pig manure to produce biogas.

In order to improve the equipment utilization rate and shorten the fermentation time, natural retting for 7 days has a certain daily biogas production advantage when the fermentation cycle is less than 20 days, but it is not significantly different from water moisture for 24 hours. Considering the total biogas production and volume loading rate, water moisture for 24 hours is the best pre-prcessing method of dry anaerobic fermentation of sugarcane leaves and pig manure when the fermentation cycle is more than 20 days.

- The analysis of gas components in different pre-prcessing biogas production shows that the water moisture for 24 hours has higher methane content, and the advantages become more significant with the prolonged fermentation time.

Due to water moisture for 24 hours need to be moisted before fermentation, and it has many advantages such as simple process, short processing time, small site, no additional add microbial and low processing cost, and it has high total biogas production and volume loading rate, so that is the best pre-processing method of dry anaerobic fermentation of sugarcane leaves and pig manure.

\section{Acknowledgments}

This work was supported by the National key R \& D plan(No. 2017YFD0800802), a grant from the Innovation-driven Development Program of Guangxi Zhuang Autonomous Region of China (No. AA18118021), the Science \& Technology Program of
Zhanjiang city of Guangdong Province of China (No.2018A03012), and the Key Laboratory of Agricultural Equipment for Tropical Crops, Ministry of Agriculture and Rural Affairs, P.R. China.

\section{Reference}

1. Li L, You X R, Sun J,et al. (2013 ) Research Progress on Comprehensive Utilization of Sugarcane Field Wastes and Sugar by-Products [J] Food Industry, (07): 170-173.

2. Wen S.B, Ge C, Li M. et al. (2017) Effects of Different Returning Field Methods on Soil Nutrient of Sugarcane Leaf [J]. Chinese Journal of Tropical Crops, 38 (8) : 1423-1426.

3. Li Y.M, Du Y.X, Zhou Y.SH etal.(2018) Research Progress of Sugarcane Leaves[J]. Food Industry, 39(1): 237-239.

4. Wang D L, Ai P, Yu L, et al.(2015) Comparing the hydrolysis and biogas production performance of alkali and acid pretreatments of rice straw using two-stage anaerobic fermentation[J]. Biosystems Engineering, 132: 47-55.

5. Fu S F, Shi X S, Wang F, et al. (2015) Comparison of thermophilic microaerobic and alkali pretreatment of sugarcane bagasse for anaerobic digestion[J]. RSC Advances, 5(78):63903-63908.

6. Monlau F, Barakat A, Trably E, et al. (2013) Lignocellulosic materials into biohydrogen and biomethane: Impact of structural features and pretreatment[J]. Critical Reviews in Environmental Science and Technology, 43(3):260-322.

7. Chen X H, Zhang Y L, Gu Y, et al.(2014) Enhancing methane production from rice straw by extrusion pretreatment[J]. Applied Energy, 122(2):34-41.

8. Michalska K, Bizukojc M, Ledakowicz S.(2015) Pretreatment of energy crops with sodium hydroxide and cellulolytic enzymes of increase biogas production[J]. Biomass and Bioenergy, 80: 213 -221.

9. Zhong W Z, Zhang Z Z, Luo Y J, et al. (2011) Effect of biolog-ical pretreatment in enhancing corn straw biogas produc-tion $[\mathrm{J}]$. Bioresource Technology,102: 11177-1118.

10. Jiao J, Wang J L, Zhang J, etal. (2012) Orthogonal Experiment of Sugarcane Leaves Dry Anaerobi Fermentation[[J]. Transactions of the Chinese Society for Agricultural Machinery,43(10):110-113. 